\title{
REVISIÓN TAXONÓMICA DE LAS ESPECIES ARBORESCENTES de Furcraea (Agavaceae) en México y Guatemala
}

\author{
Abisaí García-Mendoza \\ Jardín Botánico, Instituto de Biología, Universidad Nacional Autónoma de México. \\ A. P. 70-614, Coyoacán, 04510 México D. F., México. email: abisai@mail.ibiologia.unam.mx
}

\begin{abstract}
Resumen. Como resultado de la revisión taxonómica del género Furcraea, se reconocen seis especies arborescentes para México y Guatemala, una de ellas, de Guerrero, México, es una especie nueva para la ciencia. Se proporciona una clave de identificación, la descripción, la sinonimia, una ilustración, la distribución, el hábitat, la fenología, los nombres comunes, su utilización y una discusión breve para cada una de ellas. Las características útiles para su identificación son: margen de la hoja, ramificación de la inflorescencia, características de la flor, y forma y tamaño de los bulbilos.

Palabras clave: Agavaceae, Furcraea, Mesoamérica, México, Taxonomía.

Abstract. As a result of a revision of the genus Furcraea, six arborescent species from Mexico and Guatemala are recognized, including a new species from Guerrero, Mexico. A key, descriptions, synonymies, illustrations, distribution, habitat, phenology, common names and uses, as well as a brief discussion are included for each one. The characters with taxonomic value are margins leaf, inflorescence ramification, flower characters, and shape and size of the bulbils.
\end{abstract}

Key words: Agavaceae, Furcraea, Mesoamerica, Mexico, Taxonomy.

L a familia Agavaceae consta de ocho géneros (Dahlgren et al., 1985) y cerca de 300 especies con distribución americana, predominantemente norteamericana. En México es donde han alcanzado su mayor diversificación, aquí crecen el $75 \%$ de las especies (García-Mendoza y Galván, 1995), con un 55\% de endemismo (García-Mendoza, 1995).

Furcraea es un género morfológicamente bien delimitado pero taxonómicamente complejo. Consta de aproximadamente 25 especies de distribución neotropical. Las furcreas son arborescentes, subcaulescentes o acaules, las primeras tienen tallos de más de $1.5 \mathrm{~m}$ de altura, especies que, en su mayoría se restringen a México; el margen de las hojas es denticulado, dentado o entero; el ápice de la hoja termina en un mucrón córneo y cónico, o en un engrosamiento duro, originado por el enrollamiento de los tejidos; la superficie es lisa o rara vez presenta emergencias epidérmicas de tipo escabroso.

Las inflorescencias son de apariencia paniculada y de estructura racemosa. Existe una tendencia hacia el aumento de los racimos compuestos y otra hacia la reducción de las ramas laterales de segundo y ter- cer orden con una consiguiente condensación de las flores (Álvarez de Zayas, 1986). El grado de ramificación se incrementa del ápice a la base, de tal manera, que dan una apariencia piramidal o cónica. Las flores son bisexuales, epíginas, campaniformes, con seis tépalos, agrupados en dos series; los tépalos internos poseen una costilla central gruesa a lo largo de su longitud; los filamentos están engrosados en su parte basal y el estilo es basalmente grueso y triquetro. Los bulbilos son bracteados o foliosos; los bracteados son masivos y no emiten hojillas evidentes al momento de madurar en la inflorescencia, mientras que, los foliosos producen hojillas desde que son muy jóvenes, su forma y tamaño son estados de carácter importantes para separar especies.

El género Furcraea fue descrito por Ventenat (1793), quien lo creó a partir de la segregación de dos especies de Agave: A. foetida L. (Lineo, 1753) y A. hexapetala Jacq. (Jacquin, 1760). Ventenat dedicó el género al químico francés Antoine F. de Furcroy (1755-1809), lo que causó confusión e hizo que el nombre fuera escrito como Fourcroya, Furcroya, Furcroea o Fourcraea. Ullrich (1991) y Álvarez de Zayas (1996) discuten la 
validez del nombre, ya que la publicación original no fue de libre acceso a los botánicos de su tiempo y, cuando lo estuvo (Ventenat, 1796), había sido publicado poco antes el género Funium (Willemet, 1796), basado también en Agave foetida L. Ullrich (1991) propone que Furcraea sea un nomen conservandum, sin embargo, la propuesta no ha sido formalizada.

Durante el siglo XIX se describieron numerosas especies en Europa. Muchos nombres fueron publicados por horticultores, en catálogos que ocasionalmente incluían descripciones breves, basadas en caracteres vegetativos y de plantas inmaduras que crecían en invernaderos. En adición, no se proporcionan datos sobre su procedencia geográfica, ni se propusieron tipos, lo que hace que varias descripciones originales sean prácticamente imposibles de asignar a algún taxon conocido.

Los arreglos taxonómicos más importantes fueron hechos por Roemer (1846), Baker $(1879,1888)$ y Drummond (1907), quienes hacen proposiciones de clasificación a nivel infragenérico. Trelease (1915, 1920) reconoce cuatro especies arborescentes para México y Guatemala; Ullrich (1991a,b,c) presenta la historia taxonómica del complejo $F$. longaeva, con modificaciones a nivel taxonómico; sin embargo, no formalizó los cambios propuestos. Finalmente, García-Mendoza y Lott (1994) mencionan la necesidad de un estudio monográfico.

El género tiene un gran potencial económico como productor de fibras; de esta manera ha sido empleado por diversas etnias de América y, con este fin, algunas especies se introdujeron a varios países de África y Asia, donde tienen importancia económica.

En el presente estudio se hace una revisión de las especies arborescentes de Furcraea para México y Guatemala y se proporciona la información para su identificación; trabajo que forma parte de los estudios taxonómicos del género. Las especies aquí tratadas corresponden aproximadamente a la mitad de las que crecen en México.

\section{Método}

Se hizo un análisis exhaustivo de la literatura sobre Furcraea; se estudiaron las colecciones depositadas en los herbarios B, BM, C, CIMI, ENCB, F, G, GH, IBUG, IEB, K, LL, M, MEXU, MICH, MO, NY, QMEX, TEX, UAMIZ, UC, US, WIS y ZEA, siglas de acuerdo con Holmgren et al. (1990) y se hiceron recorridos de campo, para observar, recolectar y reconocer las épocas de floración y fructificación de las especies. Los ejemplares para herbario constan de hojas completas, ramas, flores, bulbilos y, en algunos casos fotografías. Los criterios utilizados para la delimitación de las especies son estrictamente morfológicos, las plantas colectadas se compararon con las descripciones originales y los especímenes tipo. La información fue organizada en la base de datos Biotica, modelo manejado por la Comisión Nacional para el Conocimiento y Uso de la Biodiversidad (CONABIO). Los caracteres que aportan mayor información son aquellos de la hoja, ramificación de la inflorescencia, flores y bulbilos.

\section{Resultados}

\section{Tratamiento Taxonómico}

Furcraea Vent., Bull. Soc. Philom. Corresp. 28 (Vendemiaire, an 2 de la Rep.): 1793. [Reimpreso en: Ann. Bot. (Usteri) 13: 54-60. 1796; Bull. soc. Philom. Paris 1: 65-67. 1802]. Furcroea DC., Pl. Hist. succ. 126. 1803. (orth. var). Furcroya Raf., Princ. fond. somiol. 31. 1814. (orth. var.). Fourcroya Spreng., Anleit. Kenntn. Gew. 2 (1): 238. 1817. Fourcraea Steud., Nomencl. bot.: 644. 1840. (orth. var.). TIPO: Furcraea gigantea Vent.

Funium Willemet, Ann. Bot. (Usteri) 12. 1796. Reimpreso en: Ann. Bot. (Usteri) 18: 26. 1798].

TIPO: Funium pitiferum Willemet. Roezlia Lem., Ill. Hort. $10(6): 43$. 1863. TIPO: Roezlia regia Lem. Roeslia Baill., Hist. 13:64. 1894. (orth. var.).

Plantas monocárpicas, arborescentes, subcaulescentes o acaules. Hojas arrosetadas, lanceoladas o lineares, suculentas, erectas, fibrosas, cóncavas o aplanadas, envés aquillado; base gruesa y amplia; márgenes dentados, denticulados, enteros o dentado-enteros; dientes simples o bicuspidados, sobre mamilas; ápice mucronado o endurecido por enrollamiento del margen; superficie lisa o escabrosa; coriáceas; verdes o glaucas. Inflorescencias en panículas terminales, grandes, piramidales, por lo general bulbilíferas, con ramas primarias a cuaternarias, glabras o pelosas. Brácteas del pedúnculo, bases de las ramas y de los fascículos florales, disminuyendo en tamaño hacia las partes apicales; bractéolas en igual número que las flores y basales a ellas, caedizas. Flores bisexuales, epíginas, trímeras, campaniformes, péndulas, pediceladas, fasciculadas o solitarias, blanco-verdosas o blanco-amarillentas, en ocasiones con tintes rojizos, a menudo reemplazadas por bulbilos; tépalos 6, libres, en dos series del mismo largo, los externos más angostos que los internos, elípticos, los internos con una costilla central longitudinal prominente, glabros o pelosos, sobrepuestos en sus extremos laterales, papilosos en esta zona; estambres 6, más cortos que los tépalos; filamentos engrosados en su parte, subulados hacia el ápice, papilosos; anteras oblongas, dorsifijas, ver- 
sátiles, introrsas, base sagitada, ápice emarginado; ovario ínfero, cilíndrico o trígono, prolongado en un cuello breve, glabro o peloso, 3-carpelar, 3-locular; óvulos numerosos, en dos series por lóculo, anátropos; placentación axilar; estilo basalmente grueso y triquetro, con los ángulos redondeados y suculentos, papiloso; estigma inconspicuamente trilobado. Cápsulas oblongas o subglobosas; de dehiscencia loculicida septifragal, rostradas, estipitadas. Semillas numerosas, en dos series por lóculo, aplanadas, plano-convexas, rodeadas por un ala, negras y brillantes. Bulbilos bracteados o foliosos, cónicos, ovoides o subesféricos, cubiertos con brácteas; hojillas presentes en los foliosos. Número cromosómico $n=30$.

Furcraea es un género endémico de América, presente entre los trópicos de Cáncer y de Capricornio (figura 1). Su límite norte de distribución continental se encuentra en el estado de Nayarit, México, de donde se continúa hacia el sur por Centroamérica y Sudamérica, hasta Bolivia y quizá Paraguay. En el Caribe se encuentra en todas las islas, desde las Bahamas al norte hasta Trinidad y Tobago al sur, así como en las

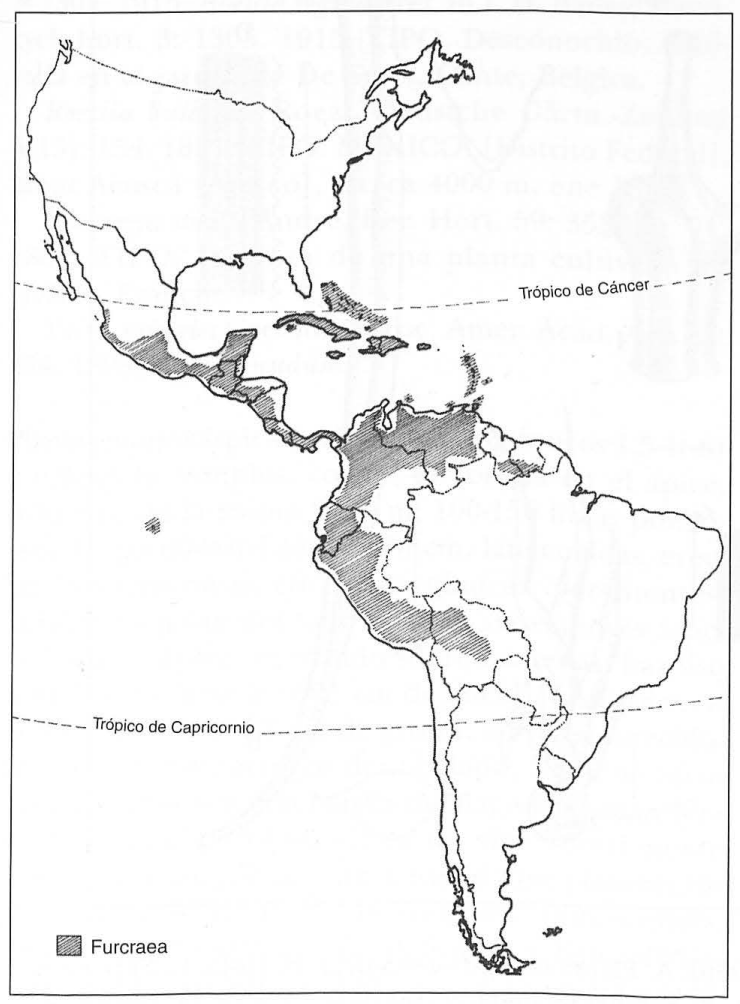

Figura 1. Distribución conocida del género Furcraea. islas Galápagos en el Pacífico. Furcraea se distribuye en dos grandes grupos, aquellas especies de las tierras bajas y tropicales cercanas al nivel del mar y aquellas de las tierras altas entre los 2000 y $3400 \mathrm{~m}$, que crecen en los bosques templados y fríos de los Andes Sudamericanos o en las montañas del centro de México y Guatemala.

Clave para la determinación de las especies arborescentes de Furcraea

1. Hojas con los márgenes denticulados.

2. Bulbilos presentes, foliosos.

3. Flores (3.5-) $4.5-5.5 \mathrm{~cm}$ de largo, ovario tomentoso; hojas 60-90(-120) × 5-10 cm, lanceoladas, glaucas.

Furcraea parmentieri

3. Flores 2.5-3.2 cm de largo, ovario pilósulo; hojas (90-) 120-160 x 6-10 cm, lineares a linear-lanceoladas, verdes.

Furcraea martinezii

2. Bulbilos ausentes.

4. Flores (2.5-) 3-3.5 cm de largo, pilósulas, amarillentas; cápsulas (3.5-)4-5 x 2.5-3(-3.5) cm, subglobosas.

Furcraea longaeva

4. Flores (5-) 5.5-6.5 (-7) cm de largo, glabras, verdosas; cápsulas 5.5-7(-8) x 2-3(-3.5) cm, oblongas.

Furcraea quicheensis

1. Hojas con los márgenes dentados o dentado-denticulados.

5. Flores 3.5-4 cm de largo; bulbilos 4-7(-8.5) x 1.2$1.6 \mathrm{~cm}$, cónicos; hojas con dientes del margen de $2-4 \mathrm{~mm}$.

Furcraea macdougallii

5. Flores 6.5-7.5 (-8) cm de largo; bulbilos 5-7 (-11) x 4.5-6.5 cm, esferoides a ampliamente cónicos; dientes del margen de $5-6(-8) \mathrm{mm}$.

Furcraea niquivilensis.

Furcraea parmentieri (Roezl ex Ortgies) García-Mend., comb. nov. Basiónimo: Yucca parmentieri Roezl ex Ortgies, Gartenflora 8(9): 278. 1859. non Carrière, 1859. TIPO. Planta cultivada en el Jardín Botánico de Berlín, sin fecha, K. Koch s.n. NEOTIPO: Beschorneria multiflora K. Koch, B! 85/88-17, designado aquí. El ejemplar elegido, es el más antiguo que se conoce de la especie y corresponde a un espécimen original de Koch. El dibujo que acompaña al ejemplar de herbario (planta completa en maceta), sirvió para elaborar la lámina publicada por Morren (1863) y que fue designada por Ullrich (1991b) como lectotipo de Furcraea bedinghausii K. Koch. Figura 2.

Beschorneria multiflora K. Koch, Wochenschr. Vereins Beförd. Gartenbaues Königl. Preuss Staaten 2(43): 338. 1859. LECTOTIPO: Planta cultivada en el Jardín Botánico de Berlín, sin fecha, K. Koch s.n., B! 85/8817, designado aquí. 


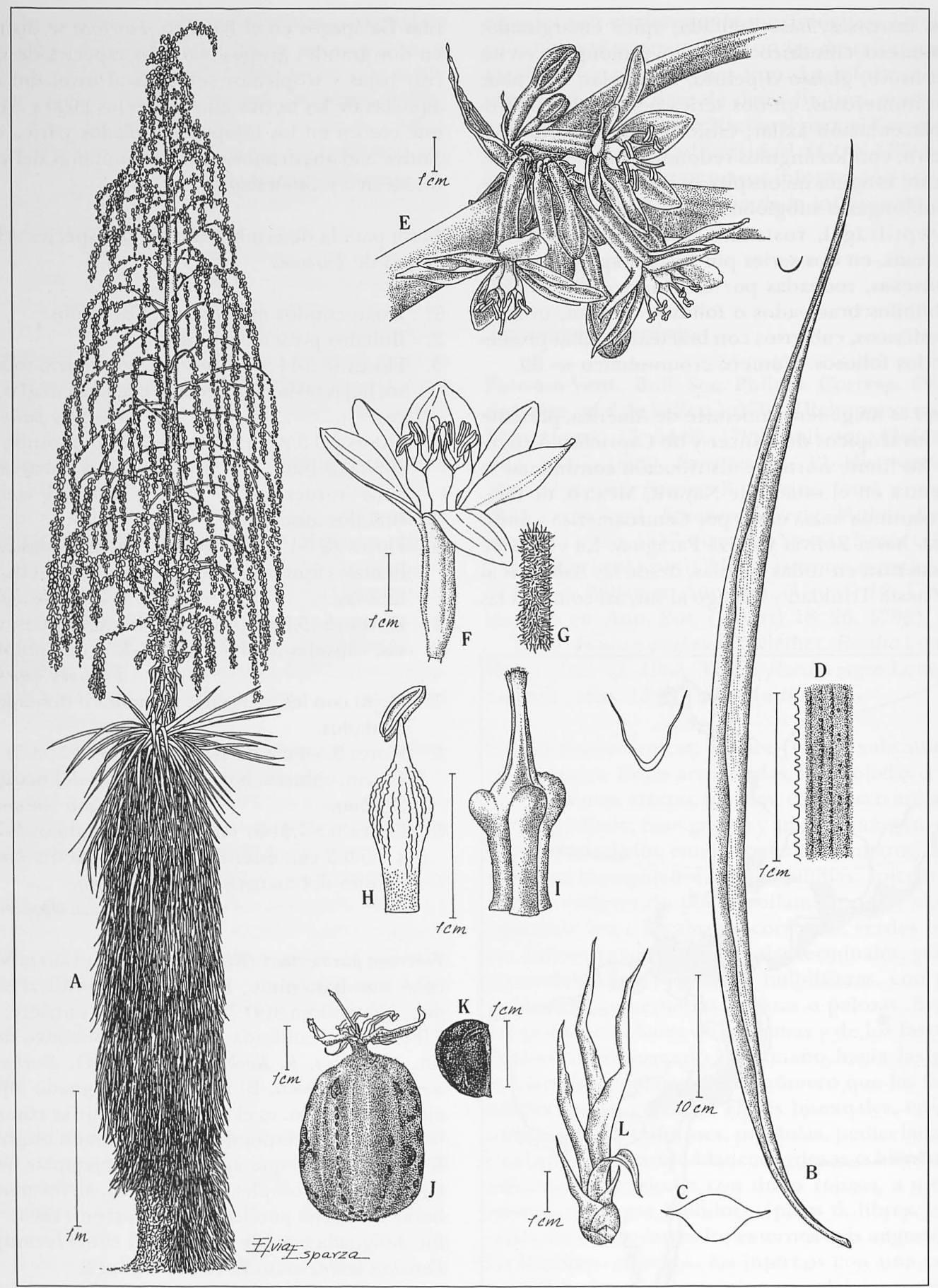

Figura 2. Furcraea parmentieri (Roezl ex Ortgies) García-Mend. A. Planta con inflorescencia. B. Hoja. C. Secciones transversales. D. Detalle del margen y superficie del envés. E. Ramilla secundaria con flores. F. Flor. G. Detalle de la pubescencia del ovario. H. Estambre. I. Estilo. J. Cápsula. K. Semilla. L. Bulbilo folioso. Ilustración basada en los especímenes Garcia-Mendoza et al. 6190, 6210, 6222 y 6230. 
Agave argyrophylla K. Koch, Wochenschr. Vereins Beförd. Gartenbaues Königl. Preuss Staaten 5(25): 199. 1862. Yucca argyrophylla Lem., Ill. Hort. 10(6): 43. 1863. Yucca argyraea Trel. in L.H. Bailey, Stand. cycl. hort. 3: 1305. 1915. TIPO. Desconocido, cultivada en el jardín de Tonel, Gante, Bélgica.

Beschorneria floribunda K. Koch, Wochenschr. Vereins Beförd. Gartenbaues Königl. Preuss Staaten 5(25): 199. 1862. TIPO. Desconocido, cultivada en el jardín de Tonel, Gante, Bélgica.

Yucca toneliana K. Koch, Wochenschr. Vereins Beförd. Gartenbaues Königl. Preuss Staaten 5(25): 199. 1862. Agave toneliana E. Morren, Belgique Hort. 13(11): 327. 1863. TIPO. Desconocido, cultivada en el jardín de Tonel, Gante, Bélgica.

Furcraea bedinghausii K. Koch, Wochenschr. Vereins Beförd. Gartenbaues Königl. Preuss Staaten 6(30): 233. 1863. TIPO MÉXICO. De una planta cultivada en el jardín de Bedinghaus en Nimy. LECTOTIPO: Litografía in Morren, Belgique Hort. 13(11): 327. 1863; designado por Ullrich, Cact. Suc. Mex. 36(3):61. 1991.

Roezlia regia Lem., Ill. Hort. $10(6)$ : 43. 1863. Lilium regium Trel. in L.H. Bailey, Stand. Cycl. Hort. 3: 1305. 1915. Lilia regia Trel. in L.H. Bailey, Stand. cycl. hort. 3: 1305. 1915, Roezlia regina Trel. in L.H. Bailey, Stand. cycl. hort. 3: 1305. 1915. TIPO. Desconocido, cultivada en el jardín de De Smet, Gante, Bélgica.

Roezlia bulbifera Roezl, Deustche Gärtn.-Zeitung 5(13): 154. 1881. TIPO. MÉXICO. [Distrito Federal], Mont Acusca [Ajusco], alt. ca 4000 m, ene 1857.

Fourcroya roezlii André, Rev. Hort. 59: 353, fig. 71. 1887. TIPO. Descrita de una planta cultivada en Hyéres, Francia.

Yucca pringlei Greenm., Proc. Amer. Acad. Arts 33: 474. 1898, nomen nudum.

Plantas monocárpicas, arborescentes, troncos 1.5-4(-8) x 0.2-0.5 m, simples, con 1(-4) rosetas en el ápice, diámetro de la roseta $2-2.5 \mathrm{~m} ; 100-150$ hojas por roseta. Hojas 60-90(-120) x 5-10 cm, lanceoladas, erectas, semicóncavas, coriáceas, glaucas, persistentes, cubriendo parte del tallo cuando secas, envés áspero hacia el ápice, muricado sobre las venas, haz liso o escábrido, base 2-4(-5) $\mathrm{cm}$ de ancho, fusiforme en corte transversal, $2-3 \mathrm{~cm}$ de grosor, ápice endurecido, menor a $1 \mathrm{~mm}$; margen denticulado, 14-20 dentículos por $\mathrm{cm}$, sobre una banda cartilaginosa amarillenta. Panículas (2.5-)4-6(-9) m de alto, fuertemente bulbilíferas, angostamente piramidales; pedúnculos 0.5-1(-1.5) m de longitud, verdosos, pubescentes; brácteas $20-75 \times 3.5-8 \mathrm{~cm}$, deltoides a lanceoladas, pardas o violetas; (50-)80-130 ramas primarias, 1-1.5(-2) $\mathrm{m}$ de largo, con los ápices colgantes, pubescentes a glabrescentes con la edad, ramas secundarias 30-60
(-90) cm de largo, colgantes, pubescentes; brácteas de la base de las ramas primarias $14-20(-35) \times 2-7 \mathrm{~cm}$, triangulares, violáceas, brácteas de las ramas secundarias 3-6 x 1-2.5 cm, lanceoladas, violáceas, glabras, brácteas de la base de los fascículos florales 1-2 x 0.4$0.8 \mathrm{~cm}$, deltoides, con tintes violáceos, pubescentes en la cara adaxial, más largas que los pedicelos, bractéolas menores a $1 \mathrm{~cm}$, deltoides, escariosas, pubescentes. Flores (3.5-) 4.5-5.5 cm de largo, en fascículos de 2-4; pedicelos $0.5-1(-1.5) \mathrm{cm}$, tomentosos; tépalos externos (1.5-)2-2.4(-2.7) x 0.4-0.6(-0.8) cm, angostamente elípticos, pubescentes por fuera, los internos (1.5-) 2-2.4(-2.7) x 0.6-0.9(-1.2) cm, elípticos, pubescentes sobre la vena media, verde-blanquecinos por fuera, blanquecinos por dentro, amarillentos después de la antesis; estambres $1-1.4 \mathrm{~cm}$ de largo, 2-4 mm en su parte más engrosada, blanquecinos; anteras 2-3 x 1-2.5 mm, amarillas; ovario (1.5-) 2-2.5(-3) x 0.2-0.7 cm, cilíndrico, tomentoso, en botón casi lanado, verde; cuello 3-5 mm; estilo 1.3-1.8 cm de largo, base 4-9 x 2.5-5 mm; estigma superficialmente trilobado. Cápsulas 4-4.5 x 3-3.5 cm, ovoides, rostro $4 \mathrm{~mm}$; pedicelos hasta $2 \mathrm{~cm}$ de largo. Semillas $9-11$ x 6-8 mm, ala $2 \mathrm{~mm}$, negras, brillantes. Bulbilos foliosos; base 1.5$2(-3) \mathrm{cm}$ de alto, (0.7-) $1-2 \mathrm{~cm}$ de ancho, ovoides, cubiertos con brácteas deltoides, escariosas, caedizas; hojillas 2.5-8 x 0.5-1 cm, lineares, denticuladas, ásperas en el envés, glaucas.

Esta especie se conoció en los tratamientos taxonómicos previos como Furcraea bedinghausii K. Koch, debido a que, él mismo Koch (1862, 1863), menciona que los nombres anteriores como Agave argyrophylla, Yucca parmentieri, Y. toneliana, Beschorneria multiflora y B. floribunda, eran nombres hortícolas. Sin embargo, Roezl en Ortgies (1859), designó con el nombre de Yucca parmentieri a la especie colectada en su ascensión al Ajusco en enero de 1857, y se refiere a ella, como "la planta más bella de la región fría de México. La inflorescencia llega a tener más de 15 pies (4.7 m) y forma una pirámide de lirios blancos ... y tiene al mismo tiempo semillas y bulbilos, los cuales producen plantas robustas rápidamente". Con esta información y la proporcionada en trabajos posteriores (Roezl 1881, 1883), no queda duda acerca de la planta a la que se está refiriendo, por lo que, el epíteto parmentieri con cuatro años más de antigüedad sobre el epíteto bedinghausii es aceptado aquí como válido. Furcraea parmentieri se reconoce fácilmente por sus hojas cortas, glaucas, con el envés áspero y una relación ancho/largo de 1:(8-) 12-15(-18); la inflorescencia es angostamente piramidal con ramas primarias y secundarias colgantes, pedúnculo corto, ramillas y flores pubescentes y bulbilos foliosos con hojillas glaucas. 
Distribución y hábitat. MÉXICO. Distrito Federal, Estado de México, Guanajuato, Hidalgo, Jalisco, Michoacán, Morelos y quizá Veracruz (Fig. 3). Cimas de las montañas más altas del Eje Neovolcánico, entre los 2300-3400 m; en bosques mesófilos de montaña con Quercus, Pinus, Abies y Cupressus; suelos de origen volcánico.

Floración y fructificación. Flores abril-julio, los colibriés las visitan al atardecer, atraídos posiblemente por el néctar; frutos y bulbilos junio-marzo. Es notoria la alta producción de bulbilos y el bajo número de cápsulas. En partes dañadas del tronco, las plantas llegan a emitir bulbilos que originan pequeñas inflorescencias. Nombres comunes. Shishi (xixi), tacamba, palma, palmilla, palmito e izote.

Usos. Religioso, las hojas y flores se emplean para adornar cruces y arcos ceremoniales en semana santa y día de muertos en el Estado de México y Michoacán. Las hojas secas se emplean como fibras para amarrar gavillas de cereales y las plantas completas se usan como cercas vivas. Cultivada como ornamental en Europa y Estados Unidos.

Especímenes examinados. DISTRITO FEDERAL. Serranía del Ajusco, 14-03-1981, R. Galván 745 (ENCB, G, TEX); 28-03-1981, R. Galván 746 (ENCB); 11-041981, R. Galván 755 (ENCB, G, IEB, TEX); 9-05-1981, R. Galván 785 (ENCB, IEB); 7-02-1982, R. Galván 1148 (ENCB); Sierra del Ajusco, 7-06-1987, A. García-M. 3178 (MEXU); 1-08-1987, A. García-M. 3500, 3501 (MEXU); 25-04-1995, A. García-M. 6032 (MEXU); Del. Cuajimalpa, La Pila, 17-04-1996, A. García-M. et al. 6188 (MEXU); Volcán Pelado, 1-05-1996, A. Garcia-M. et al. 6208, 6209, 6210, 6211 (MEXU); Parres, 29-05-1981, L. Hernández, et al. 105 (ENCB, MEXU, UAMIZ); Cerro Pelado, 13-07-1960, H. Iltis et al. 216 (ENCB, F, IEB, MEXU, MICH, US); Volcán Xitle, 10-09-1950, E. Matuda 19623 (F, MEXU, UC); Cañada de Contreras, 27-04-1947, F. Miranda 4101 (MEXU); Los Dinamos, 13-01-1951, E. Ogden 5138 (MICH); Serranía de Ajusco, 17-08-1897, C.G. Pringle 6669 (B, BM, C, G, GH, K, M, MEXU, MO, NY, UC, US); 18-04-1898, C.G. Pringle 6801 (BM, F, G, GH, M, MEXU, MO, NY, UC, US); Xitli, 08-1932, A. Ramirez 1222 (MEXU); Sierra del Ajusco, 18-07-1901, J.N. Rose y R. Hay 5542 (US); Xitle, 17-02-1952, J. Rzedowski 776 (ENCB); Contreras, 15-05-1954, J. Rzedowski s/n (ENCB); Monte Alegre, 29-11-1981, J. Rzedowski 37659 (ENCB). ESTADO DE MÉXICO. Mpio. de Tlalmanalco, San Rafael, 16-051965, J. Espinoza 665 (ENCB, MICH); Mpio. Valle de Bravo, La Mesa, 9-04-1994, A. García-M. et al. 5907 (MEXU); Ocoyoacac, 17-04-1994, A. García-M. et al. 6189, 6190 (MEXU); Mpio. Tianguistengo, Mumanatl, 21-05-1996, A. Garcia-M. et al. 6219, 6220 (MEXU); Mpio. Temascaltepec, Oxtotilpan, 21-05-1996, A. Gar-
cia-M. et al. 6221 (MEXU); La Mesa, 21-05-1996, A. Garcia-M. et al. 6222 (MEXU); Mpio. Aculco, La Toma, 25-05-1996, A. Garcia-M. et al. 6239 (MEXU); Toluca to Zitácuaro, 5-10-1982, H. Iltis et al. 28769, 28774 (IEB); Ixtaccíhuatl, 13-02-1993, F. Palma 751 (MEXU); Villa del Carbón, 22-04-1967, E. Matuda 37560 (MEXU); Hacienda Nado, 1-05-1967, E. Matuda 37561 (ENCB, MEXU, UAMIZ); 29-04-1967, E. Matuda 37618 (MEXU); Valle de Bravo, 11-05-1970, E. Matuda s/n (MEXU); Sierra de las Cruces, 10-09-1900, C.G. Pringle 9219 (GH, US); Near Salazar, 14-09-1903, J.N. Rose y J.H. Painter 7013 (GH, NY, US). GUANAJUATO. Mpio. Jerécuaro, El Yesquero, 24-10-1986, H. Diaz-B. 3312 (IEB). HIDALGO. Sierra de Pachuca, 8-07-1959, J. Beaman 2766 (GH, ENCB, TEX, UC); Mpio. El Chico, Las Ventanas, 16-05-1981, R. Galván 792 (ENCB, MEXU, TEX); 9-06-1996, A. García-M. 6242 (MEXU); Real del Monte, 7-05-1967, E. Matuda 37570 (MEXU, UAMIZ); Mpio de Tulancingo, Tejocotal, 17-04-1965, E. Matuda 37609 (MEXU); Hidalgo, 27-03-1966, E. Matuda 37611 (MEXU); Las Ventanas, 17-07-1976, M. Medina 1437 (ENCB, MEXU, MICH, MO); 7-06-1981, M. Medina 2256 (ENCB, IBUG, MEXU, UAMIZ); Peña del Cuervo, 22-11-1948, F. Miranda 4824 (MEXU); Sierra de Pachuca, 4-08-1898, C.G. Pringle 6973 (GH, MEXU); 21-02-1899, C.G. Pringle 6991 (BM, F, G, GH, K, M, MEXU, NY, MO, UC, US); Mountains near Pachuca, 1-06-1899, J.N. Rose y W. Hough 4455 (US); Sierra de Pachuca, 1-09-1903, J.N. Rose y J.H. Painter 6743 (US); Las Ventanas, 17-07-1976, J. Rzedowuski 1437 (ENCB); Los Gavilanes, 10-03-1966, J. Rzedow 22035 (ENCB, F, MICH); Las Ventanas, 22-06-1975, J. Rzedowski 33290 (ENCB). JALISCO. Mpio. Cuautitlán, Sierra de Manantlán, Cerro de las Capillas, 9-03-1987, M. Cházaro s/n (IBUG); El Guízar, H. Iltis et al. 29394 (WIZ, ZEA); El Chante, 15-04-1949, R. McVaugh $s / n$ (MICH); Las Capillas, 28-04-1988, F.J. Santana y R. Cuevas 3431 (ZEA); Volcano of Colima, 7-06-1893, C.G. Pringle 5476 (MEXU). MICHOACÁN. Mpio. Pátzcuaro, Joya Las Navas, 3-06-1986, H. Díaz-B. 2300 (ENCB, IBUG, IEB); Mpio. Zitácuaro, La Dieta, 21-05-1996, A. Garcia-M. et al. 6223 (MEXU); Mpio. Cd. Hidalgo, La Mina, 22-05-1996, A. Garcia-M. et al. 6224 (MEXU); Pino Gordo, 22-05-1996, A. García-M. et al. 6228 (ENCB, MEXU); Mpio. Villa Escalante, carr. OpopeoTacámbaro, 22-05-1996, A. Garcia-M. et al. 6230, 6231, 6233, 6234 (MEXU); Nahuatzen, 23-05-1996, A. Garcia-M. et al. 6235 (MEXU); Mpio. Nahuatzen, Cerro Pilón, E. García y E. Pérez 3340 (IEB); Mpio. Parangaricutiro, San Nicolás, 4-07-1996, I. García-R. 4009 (CIMI, MEXU); Mpio. Uruapan, Agahuan, 27-09-1996, I. Garcia-R. et al. 4275 (CIMI, MEXU); Mpio. Parangaricutiro, Cerro Tancítaro, 25-04-1997, I. García-R. et al. 4669 (CIMI, MEXU); Mpio. Tangancícuaro, Cerro 


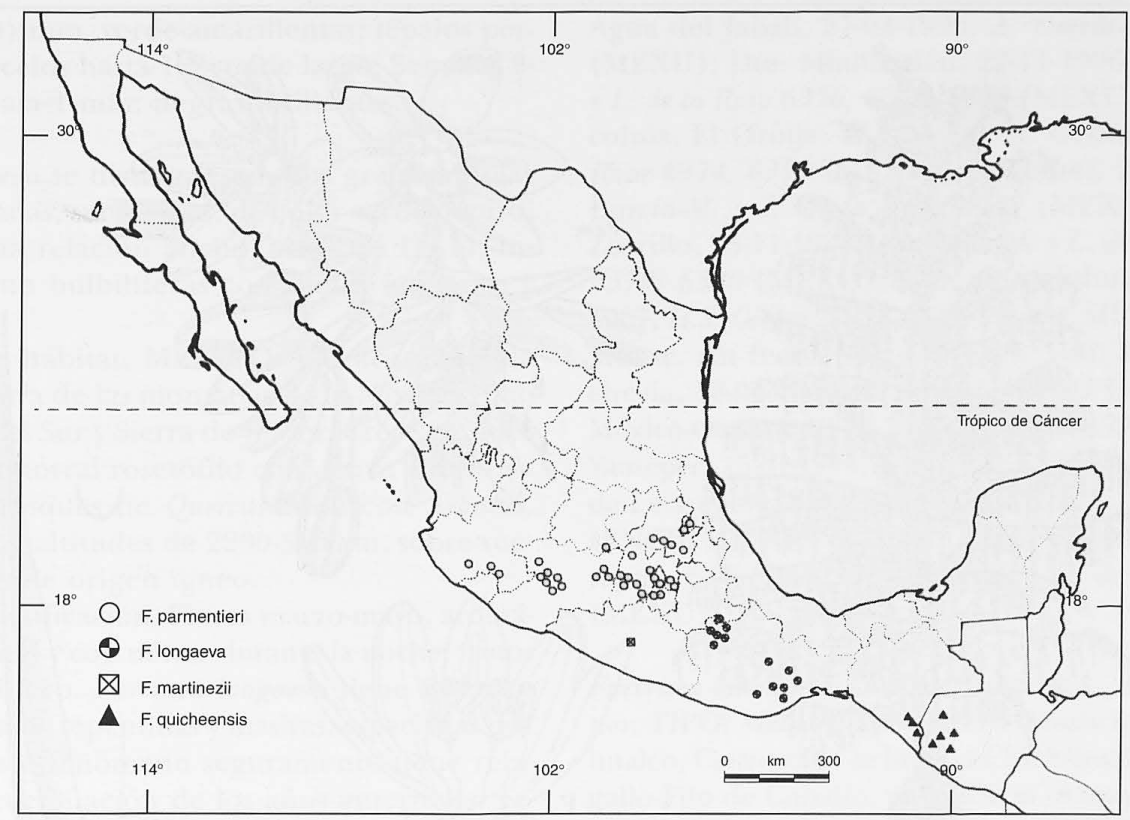

Figura 3. Distribución de Furcraea parmentieri, F. longaeva, F. martinezii y F. quicheensis.

Patambán, L. Torres 886 (IEB). MORELOS. Lagunas de Zempoala, 26-04-1995, A. García-M. 6035 (MEXU); Carr. Huitzilac-Zempoala, 1-05-1996, A. García-M. et al. 6214 (MEXU); Mpio. Huitzilac, Coajomulco, 3009-1998, A. Garcia-M. et al. 6726 (MEXU). VERACRUZ. Sierra de Huayacocotla (citada por Cházaro, 1989).

Furcraea longaeva Karw. \& Zucc., in Zucc., Flora 15(2), beiblatt 5:94. 1832. TIPO: MÉXICO. Crescit in summo monte Tanga, provinciae Oaxaca, 10000 pedes supra Oceanum in declivibus Quercubus et Arbutis consitis., may 1829, W. F. Karwinsky s. n. LECTOTIPO: Litografía in Zuccarini, Nova Acta Phys.-Med. Acad. Caes. Leop.Carol. Nat. Cur. 16(2), t. 48. 1833; designado por Ullrich, Cact. Suc. Mex. 36(3): 61. 1991. Figura 4.

Plantas monocárpicas, arborescentes, troncos 3-6(-9) x 0.4-0.7 m, simples, con una roseta de hojas, corteza rojo-violeta, 150-300 hojas por roseta. Hojas 120-160 x 10-14(-17) cm, linear-lanceoladas, erectas, cóncavas, suculentas, verde oscuras, persistentes, cubriendo todo el tallo o parte de él, superficie lisa en ambas caras, o algo escabrosas en el ápice del envés, base 5-8(-11) $\mathrm{cm}$ de ancho, depreso-obovadas en corte transversal, 5-7 cm de grosor, ápice endurecido, caedizo; margen denticulado, 12-27 dientecillos por $\mathrm{cm}$, sobre una banda verde-amarillenta. Panículas 3-6(-9) $\mathrm{m}$ de alto, no bulbilíferas, piramidales; pedúnculos $0.3-1 \mathrm{~m}$ de longitud, verdes, glabros, brácteas $50-90 \times 7.5-15 \mathrm{~cm}$, deltoides, denticuladas, pardo-violetas; 60-100 ramas primarias, $0.8-1 \mathrm{~m}$ de largo, glabras o glabrescentes, verde-amarillentas, $30-50$ ramas secundarias, $10-30 \mathrm{~cm}$ de largo, glabrescentes o glabras, verde-amarillentas, ocasionalmente en fascículos de 3-4, ramas terciarias $5-15 \mathrm{~cm}$ de largo, glabrescentes, verde-amarillentas, ramas cuaternarias menores a $4 \mathrm{~cm}$ de largo ocasionales; brácteas de la base de las ramas primarias 30$35 \times$ (4-) $8-10 \mathrm{~cm}$, deltoides, glabras, pardo-violetas, brácteas de las ramas secundarias 4-7 x 2-4 mm, pardas, presentes en las inflorescencias jóvenes, brácteas de las ramas terciarias y cuaternarias menores a $2 \mathrm{~mm}$, translúcidas, escariosas, caedizas, brácteas de la base de los fascículos florales y bractéolas inconspicuas, más cortas que los pedicelos. Flores (2.5-) 3-3.5 cm de largo, en fascículos de 3-6; pedicelos 0.2-0.5 (-1) cm, glabrescentes o glabros; tépalos externos (1.2-) 1.5-2 x 0.4$0.6 \mathrm{~cm}$, angostamente elípticos, pilósulos por fuera, los internos (1.2-) 1.5-2 x 0.5-1 cm, elípticos, pilósulos, blanco-verdosos por fuera, amarillentos por dentro; estambres 8-11 mm de largo, 1.5-3.5 mm en su parte más engrosada, blanquecinos; anteras 2.2-6 x 1-2 mm, amarillo-anaranjadas; ovario (1-) 1.5-2 x 0.2$0.5 \mathrm{~cm}$, cilíndrico, pilósulo, verde; cuello $1-2 \mathrm{~mm}$, puberulento; estilo $1-1.7 \mathrm{~cm}$ largo, base 4.5-6 x 2.5-4.5 $\mathrm{mm}$, blanquecino; estigma trilobado, ciliado. Cápsulas (3.5-) 4-5 x 2.5-3(-3.5) cm, subglobosas u oblongas, 


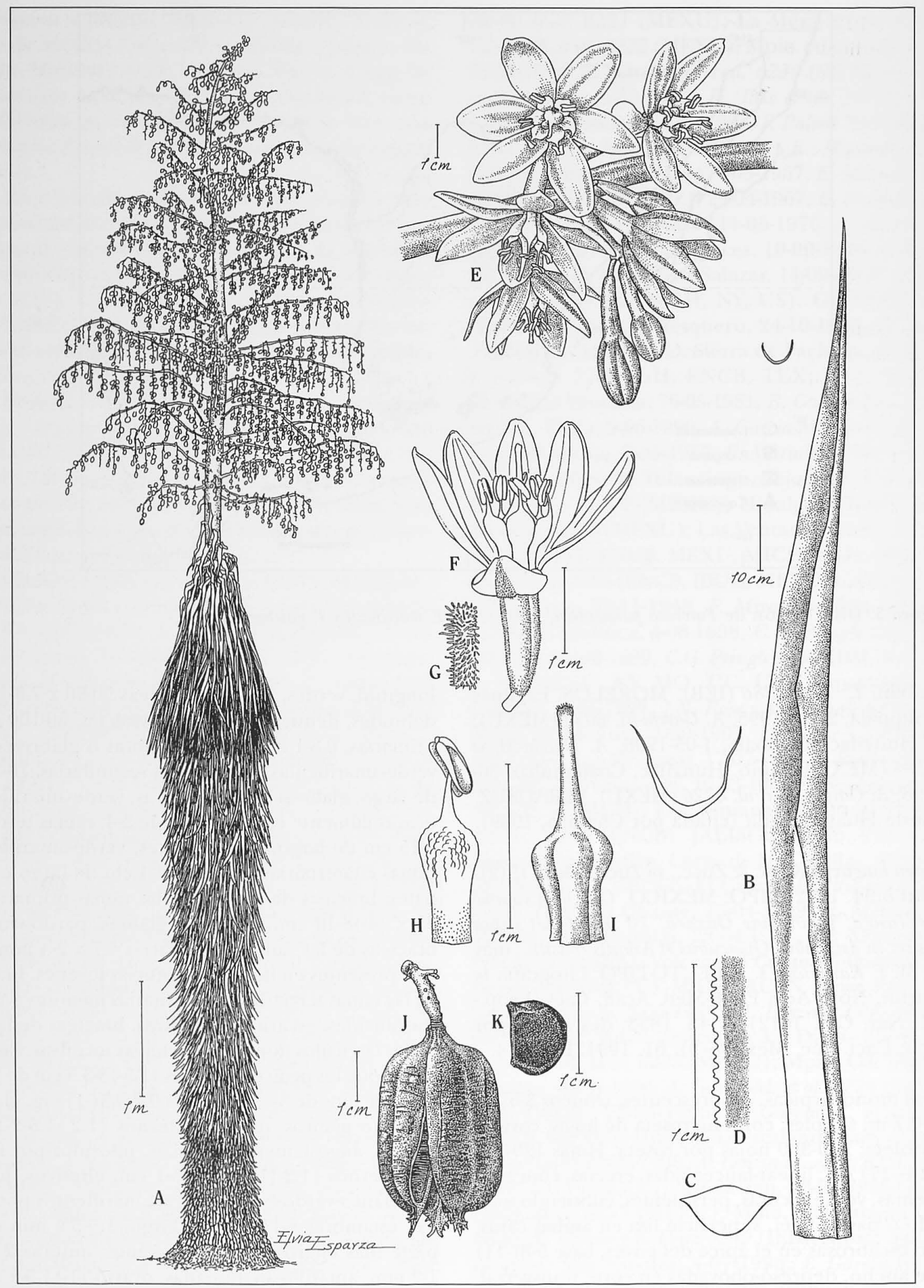

Figura 4. Furcraea longaeva Karw. \& Zucc. A. Planta con inflorescencia. B. Hoja. C. Secciones transversales. D. Detalle del margen. E. Ramilla terciaria con flores. F. Flor. G. Pubescencia del ovario. H. Estambre. I. Estilo. J. Cápsula. K. Semilla. Ilustración basada en los especímenes Garcia-Mendoza et al. 6055, 6159, 6203 y 6378. 
rostro 3-6 (-10) $\mathrm{mm}$, verde-amarillentas; tépalos persistentes, pedicelos hasta $1.5 \mathrm{~cm}$ de largo. Semillas 9 $10 \times 7-8 \mathrm{~mm}$, ala $1 \mathrm{~mm}$, negras, brillantes.

Furcraea longaeva se distingue por sus grandes hojas linear-lanceoladas, suculentas, de color verde oscuro, que tienen una relación ancho/largo de 1:9-11; inflorescencias no bulbilíferas con ramas terciarias y cuaternarias.

Distribución y hábitat. MÉXICO. Oaxaca y Puebla (figura 3). Nativa de las montañas de la Mixteca Alta, Sierra Madre del Sur y Sierra de Juárez. Crece en sitios abiertos del matorral rosetófilo con Agave, Dasylirion y Nolina; en bosques de Quercus-Pinus con Arbutus, Brahea y Clethra; altitudes de 2200-3100 m, sobre suelos pedregosos de origen ígneo.

Floración y fructificación. Flores marzo-mayo, aromáticas (olor a miel) y con néctar durante la noche; frutos en octubre-febrero. Furcraea longaeva tiene floraciones espectaculares repentinas y masivas, espaciadas por varios años; este fenómeno seguramente tiene relación con la precipitación de los años anteriores.

Nombres comunes. Pescadillo, tehuizote, palma, palmita, palmilla, cedro, yacktobiyack, yahuindayasi y pita. Usos. Doméstico, las hojas machacadas en agua se usan para lavar utensilios y ropa; ya secas se emplean para hacer amarres; las flores se usan como forraje y en los troncos secos se crían abejas. Cultivada como ornamental.

Especímenes examinados. OAXACA. Dto. Teposcolula, Mpio. Nopala, Cerro Pericón, 6-07-1986, A. García-M. et al. 2326 (MEXU); Dto. Coixtlahuaca, Mpio. Tepelmeme, El Rodeo, 9-07-1986, A. García-M. et al. 2467 (MEXU); Cerro Pericón, 14-05-1988, A. García-M. 3960 (MEXU); Dto. Miahuatlán, Santa María Coatlán, 2004-1990, A. García-M. et al. 4696-A (MEXU); Dto. Ixtlán, Mpio. Amatlán, Cuajimoloyas, 2-02-1993, A. Garcia-M. et al. 5764 (MEXU); 15-08-1993, A. GarciaM. et al. 5823 (MEXU); Dto. Teposcolula, Barranca del Chilaco, 30-04-1995, A. Garcia-M. 6055 (MEXU); Cerro Garabatal, 30-04-1995, A. Garcia-M. 6058 (MEXU); El Organito, 21-03-1996, A. Garcia-M. y L. de la Rosa 6159, 6160 (MEXU); Falda de las honduras, 21-03-1996, A. García-M. y L. de la Rosa 6161, 6162 (MEXU); Cerro Flecha, 22-03-1996, A. Garcia-M. y L. de la Rosa 6165, 6166 (MEXU); Dto. Miahuatlán, Mpio. San Pablo Coatlán, 23-03-1996, A. Garcia-M. y L. de la Rosa 6170 (MEXU); Cerro Yagaley, 23-03-1996, A. Garcia-M. y L. de la Rosa 6171 (MEXU); Cerro Cedro, 23-03-1996, A. Garcia-M. y L. de la Rosa 6172 (MEXU); Dto. Teposcolula, El Frijolillo, 27-04-1996, A. GarciaM. et al. 6200, 6201 (MEXU); Cerro Campana, 27-041996, A. Garcia-M. et al. 6202 (MEXU); La Cueva Iglesia, 27-04-1996, A. Garcia-M. et al. 6203 (MEXU);
Agua del Jabalí, 27-04-1996, A. Garcia-M. et al. 6204 (MEXU); Dto. Miahuatlán, 22-11-1996, A. Garcia-M. y L. de la Rosa 6356, 6357, 6358 (MEXU); Dto. Teposcolula, El Oroije, 25-11-1996, A. García-M. y L. de la Rosa 6374, 6375 (MEXU); El Laurel, 25-11-1996, A. Garcia-M. y L. de la Rosa 6377 (MEXU); Agua del Zorrillo, 25-11-1996, A. García-M. y L. de la Rosa 6378, 6379, 6380 (MEXU); Sierra de Mahuisapan, 24-111967, H.S. Gentry 22471 (GH, MEXU, MICH); In Tanga Monte, sin fecha, Karwinski s.n. (G); Serradero Lechevía, 18-01-1966, E. Matuda 37493 (MEXU); Carr. México-Oaxaca, 19-03-1967, E. Matuda 37548 (MEXU); Yautepec, 15-01-1971, E. Matuda 38274 (MEXU); Sierra de Lecheguía, Yautepec, 11-05-1972, E. Matuda 38438 (ENCB, MEXU). PUEBLA. Mpio. Zapotitlán, Xochiltepec, 6-05-1997, A. Garcia-M. y L. de la Rosa 6497 (MEXU).

Furcraea martinezii García-Mend. \& L. de la Rosa, sp. nov. TIPO: MÉXICO. Guerrero: Municipio de Chichihualco, Crucero de la brecha Chichihualco-Puerto del gallo-Filo de Caballo, alt. 2400 m, 8 may 1997 (b, fr), A. Garcia-Mendoza y L. de la Rosa 6526 (HOLOTIPO, MEXU; ISOTIPOS: por distribuirse). Figura 5.

Plantae monocarpicae, arborescentes; folia (90-) 120$160 \mathrm{~cm}$ longa, $6-10 \mathrm{~cm}$ lata, linearia vel lineari-lanceolata, margine denticulata, 15-19 denticulis per centimetrum. Paniculae bulbiliferae, pyramidali, ramis primariis ad tertiarias. Flores $2.5-3.2 \mathrm{~cm}$ longi, glabrescentes. Bulbili foliosi, basi $2.5-4.5 \mathrm{~cm}$ diametro, $1.5-3.5 \mathrm{~cm}$ alti, robusti, ovoidei, bracteis foliosis rubellis obtecti, foliis $10-20 \mathrm{~cm}$ longis, $0.8-2 \mathrm{~cm}$ latis, linearibus, viridulis, margine denticulatis.

Plantas monocárpicas, arborescentes, troncos 2-4(-8) $\mathrm{x}$ 0.3-0.4 m, simples, con una roseta de hojas en el ápice, 150-200 hojas por roseta. Hojas (90-) 120-160 x 6-10 cm, lineares a linear-lanceoladas, erectas, cóncavas, subcoriáceas, verde-oscuras, persistentes, cubriendo parte del tallo, superficie lisa, algo escabrosa en el ápice del envés, base 4-6 cm de ancho, depreso-obovada en corte transversal, $45 \mathrm{~cm}$ de grosor, ápice endurecido, caedizo; margen denticulado, 15-19 dientecillos por $\mathrm{cm}$, sobre una banda verde-amarillenta. Panículas 6-8 $\mathrm{m}$ de alto, bulbiliferas, piramidales; pedúnculos $0.5-1.5 \mathrm{~m}$ de longitud, verdes, glabros, brácteas $40 \times 4-7 \mathrm{~cm}$, deltoides, denticuladas, pardas; 100-200 ramas primarias, 1-1.5(-2) m de largo, glabras, verdes, ramas secundarias $10-25 \mathrm{~cm}$ de largo, glabras, verdes, ramas terciarias $3-7 \mathrm{~cm}$ de largo, glabras, verdes; brácteas de las bases de las ramas caedizas, presentes solo en inflorescencias jóvenes, brácteas de la base de los fascículos florales y bractéolas, inconspi- 


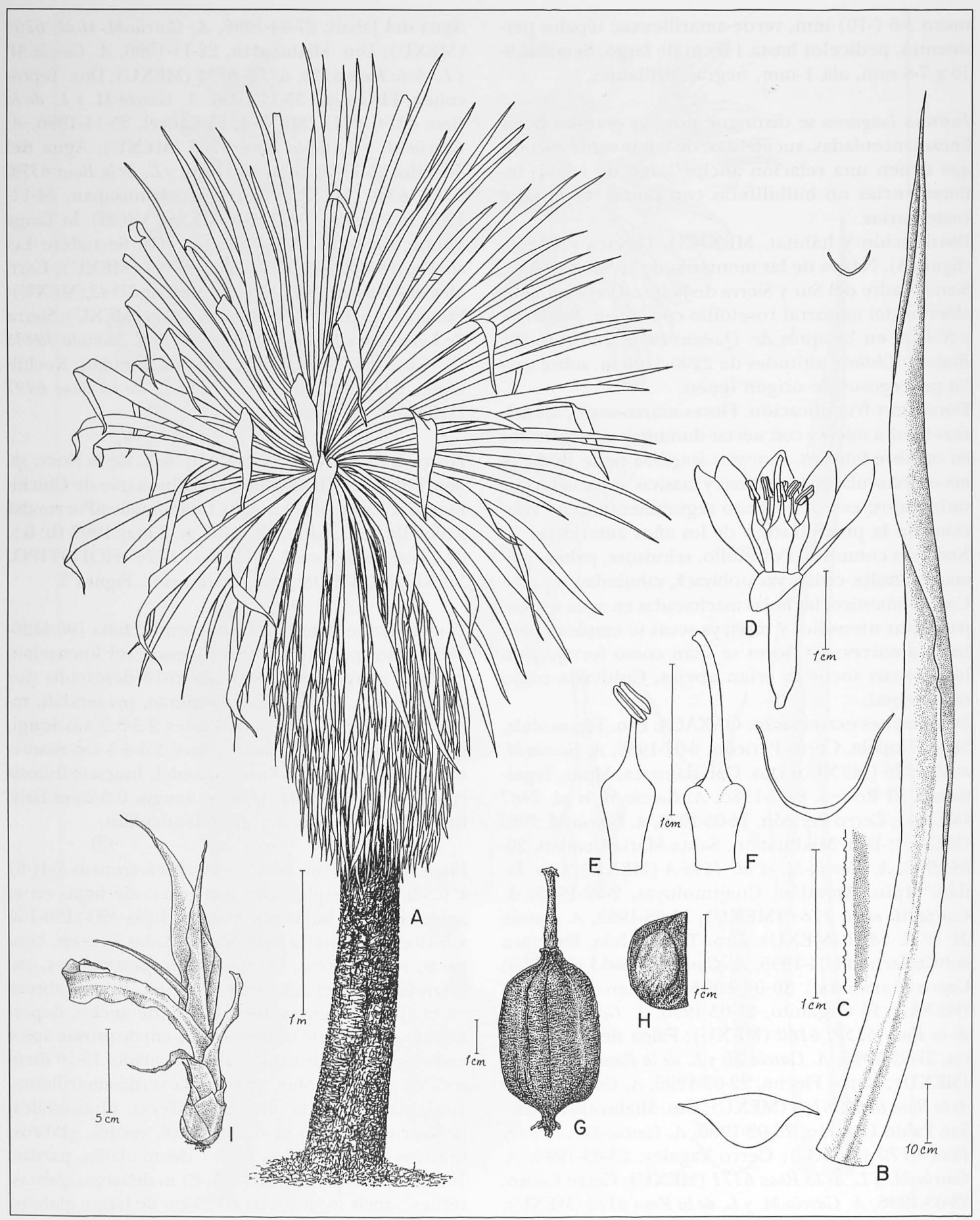

Figura 5. Furcraea martinezii García-Mend. y L. de la Rosa. A. Planta completa. B. Hoja y sus secciones transversales. C. Detalle del margen. D. Flor. E. Estambre. F. Estilo. G. Cápsula. H. Semilla. I. Bulbilo. Ilustración basada en los especimenes Matuda 38619 y Garcia-Mendoza et al. 6521, 6738. 
culas, más cortas que los pedicelos. Flores $2.5-3.2 \mathrm{~cm}$ de largo, en fascículos de 3-4; pedicelos 4-6 $\mathrm{mm}$, glabros; tépalos externos 1.2-1.6 x 0.3-0.4(-0.6) $\mathrm{cm}$, angostamente elípticos, los internos 1.2-1.6 x 0.5-0.7 (-0.8) $\mathrm{cm}$, elípticos, pilósulos en la base, blanquecino-verdosos por fuera, blanquecinos por dentro; estambres 9-11 mm de largo, 2-3 mm en su parte más engrosada, papilosos en la base, blanquecinos; anteras 2.5-3 x 1-2 mm, amarillas; ovario 1.3-1.5 x 0.3-0.4 cm, cilíndrico, pilósulos, verde; cuello 1-2 mm, en ocasiones puberulento; estilo 0.9-1.2(-1.6) $\mathrm{cm}$ de largo, base 4.5-5.5 x 3-4.5 mm, truncada, profundamente trisulcada, papilosa, blanquecina; estigma trilobado. Cápsulas 3.5-4.5(-5) x 3-4 cm, subglobosas a oblongas, verde-amarillentas; rostro 4-6 $\mathrm{mm}$, pedicelos hasta 1.5 $\mathrm{cm}$ de largo. Semillas 11-12(-14) x 7-8(-9) mm, ala 2 $\mathrm{mm}$, negras, brillantes. Bulbilos foliosos; base 2.5-4.5 $\mathrm{cm}$ de alto, $1.5-3.5 \mathrm{~cm}$ de ancho, robustos, ovoides, cubiertos por brácteas foliosas rojizas; hojillas 10-20 x 0.8-2 cm, lineares, verdosas, margen denticulado.

Furcraea martinezii es semejante a $F$. longaeva, con la que comparte el tamaño de los tallos, tamaño de rosetas e inflorescencia piramidal con ramas primarias a terciarias; se diferencia de ésta por tener bulbilos foliosos con brácteas también foliosas, baja producción de cápsulas; hojas más angostas, con una relación ancho: largo de 1:12-15(-17); flores más pequeñas y semillas más grandes. F. martinezii se encuentra separada geográficamente por más de $150 \mathrm{~km}$ en línea recta de las poblaciones más cercanas de $F$. longaeva y $F$. parmentieri y crece, además, en bosques más húmedos.

La especie se dedica a Esteban Martínez Salas, colector de la Flora Mexicana y en particular de numerosas agaváceas.

Distribución y hábitat. MÉXICO. Endémica de Guerero (figura 3), conocida de algunas montañas en la Sierra de Igualatlaco; crece sobre suelos arenosos derivados de cenizas volcánicas entre 2360-2450 m, en bosque mesófilo de montaña con Pinus, Quercus, Alnus, Ostrya y Clethra.

Floración y fructificación. Florece en abril, fructifica y produce bulbilos de noviembre a mayo.

Nombre común. Magueyito.

Usos. Artesanal y religioso; de las hojas se extraía ixtle y con sus flores se adornan las iglesias durante las fiestas de semana santa (A. Rodríguez, com. pers.). Paratipos. GUERRERO. Mpio. Chichihualco, Carrizalillo a Filo de Caballo, 2-12-1988, A. Garcia-M. et al. 4104, 4105 (MEXU); Oeste de Filo de Caballo, 8-051997, A. Garcia-M. y L. de la Rosa 6521, 6522, 6523 (MEXU); Brecha Chichihualco-Puerto del Gallo-Filo de Caballo, 8-05-1997, A. Garcia-M. y L. de la Rosa 6524,
6525 (MEXU); Ocoximba, Fresno, Chilpancingo, 104-1974, E. Matuda 38619 (LL).

Furcraea quicheensis Trel., Trans. Acad. Sci. St. Louis 23:148, pl. 29. 1915. TIPO. GUATEMALA. El Quiché, Between Quiché and Totonicapan, 17 may 1906 (fl), Cook n.b. 421 (HOLOTIPO: US 692146, microficha MEXU! ex US). Figura 6.

Plantas monocárpicas, arborescentes, troncos 1-2 x 0.2$0.4 \mathrm{~m}$, simples o ramificados hasta $4-5$ veces, diámetro de la roseta $2-3 \mathrm{~m} ; 60-100$ hojas por roseta. Hojas 80-120(-150) x 7-10(-14) cm, lanceoladas, erectas, aplanadas a algo acanaladas, glaucas, persistentes, envés con venación prominente, haz liso, base $4-7 \mathrm{~cm}$ de ancho, ampliamente triangular en corte transversal, 3-6 cm de grosor; ápice endurecido, redondeado; margen denticulado, 8-10 dientecillos por $\mathrm{cm}$, sobre una banda cartilaginosa. Panículas 2-5 m de alto, no bulbilíferas, angostas, oblongas, con flores en 2/ 3-3/4 partes superiores; pedúnculos 1-2 m de longitud, verdes, glabros; brácteas $20-60 \times 5-12 \mathrm{~cm}$, triangulares; 50-80 ramas primarias, (15-)50-70(-100) cm de largo, glabras; ramas secundarias de $10 \mathrm{~cm}$, ocasionales, glabras; brácteas de la base de las ramas primarias 6-17 x 2-4 cm, lanceoladas a ovado-lanceoladas, glabras, pardo-oscuras; brácteas de la base de los fascículos florales $4-8 \times 0.5-2 \mathrm{~cm}$, deltoides, glabras, rojizas, escariosas, más largas que los pedicelos, bractéolas menores a $1.5 \mathrm{~cm}$, deltoides, escariosas. Flores (5-)5.5-6.5(-7) cm de largo, en fascículos de 35 ; pedicelos 1-2(-3) cm, glabros; tépalos externos (2) 2.5-3(-3.5) x 0.4-0.7 (-0.9) cm, elípticos, los internos (2-)2.5-3(-3.5) x 0.6-0.9(-1.2) cm, elípticos, vena media prominente, suculentos, glabros, verdes con tintes parduzcos por fuera, verdoso-blanquecinos por dentro; estambres $1-1.4 \mathrm{~cm}$ de largo, 2-4 $\mathrm{mm}$ en su parte más engrosada, blanquecinos; anteras 2-2.5 x 1-1.5 mm, amarillas; ovario 2.5-3(-3.9) x 0.3-0.5 (-0.7) $\mathrm{cm}$, cilíndrico, glabro, verde-oscuro o verde-pardo; cuello menor a $2 \mathrm{~mm}$; estilo $1.3-1.7 \mathrm{~cm}$ de largo, base 4-6 x 2-4 mm; estigma superficialmente trilobado. Cápsulas 5.5-7(-8) x 2-3(-3.5) cm, oblongas; rostro 5 $\mathrm{mm}$, pedicelos $2-3 \mathrm{~cm}$ de largo. Semillas $8-10$ × 5-7 $\mathrm{mm}$, ala $1 \mathrm{~mm}$, negras, brillantes.

Furcraea quicheensis se caracteriza por sus panículas angostas, no bulbiliferas, flores grandes, glabras, suculentas, brácteas de la base de los fascículos florales más largas que los pedicelos, cápsulas oblongas y hojas glaucas con una relación ancho/largo de 1:10-15 (-20). Distribución y hábitat. GUATEMALA Y MÉXICO. Tierras altas del Quiché y Huehuetenango en Guatemala y Sierra del Soconusco en Chiapas (figura 3). 


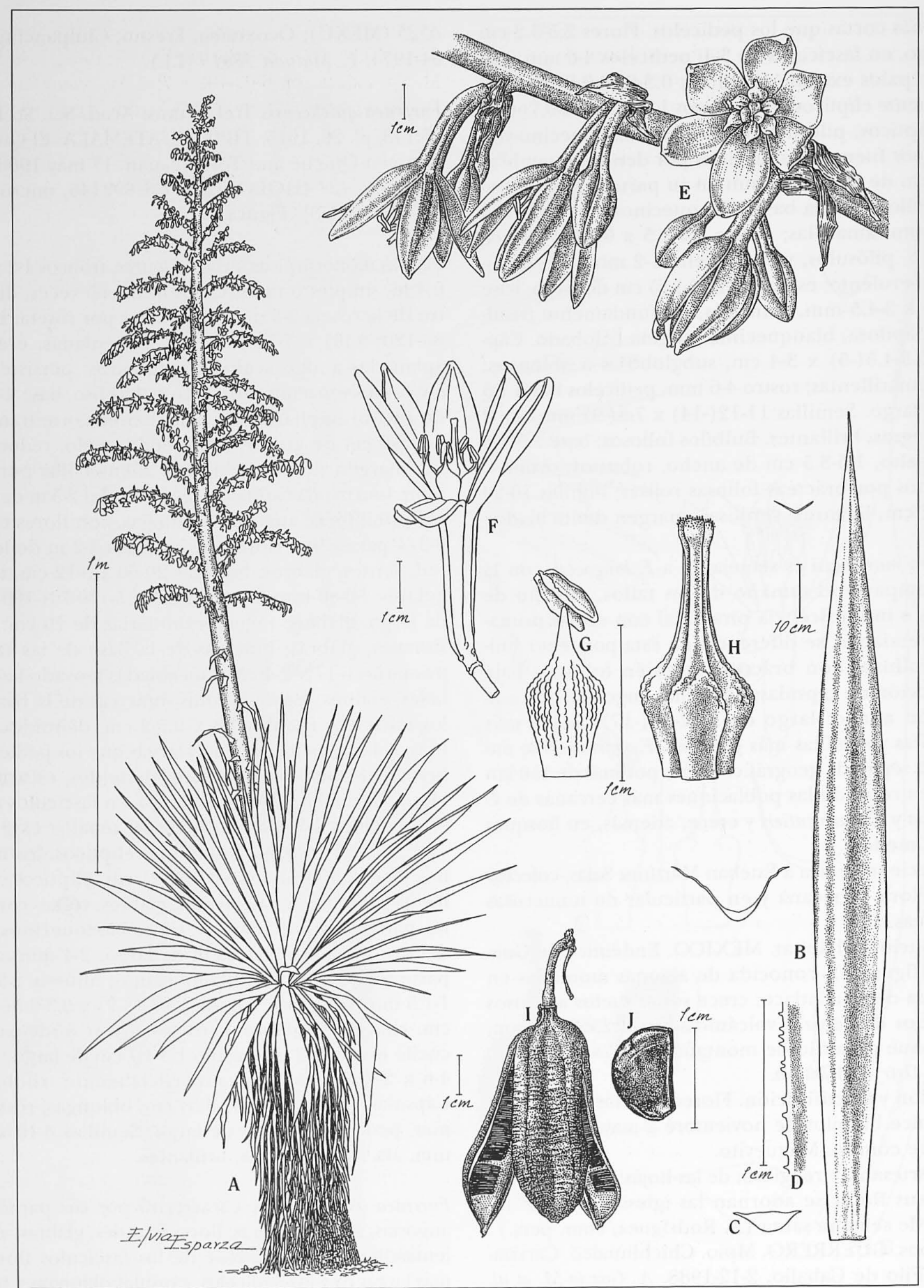

Figura 6. Furcraea quicheensis Trel. A. Planta con inflorescencia. B. Hoja. C. Secciones transversales. D. Detalle del margen. E. Ramilla primaria con flores. F. Flor. G. Estambre. H. Estilo. I. Cápsula. J. Semilla. Ilustración basada en los especímenes Garcia-Mendoza et al.3563, 6268, 6286 y 6600. 
Cultivada o escapada de cultivo; altitud 2000-3300 m, sobre suelos derivados de cenizas volcánicas; rara vez en sitios expuestos del bosque mesófilo de montaña con Pinus, Quercus, Alnus, Ulmus, Chiranthodendron, Clethra y Arbutus.

Floración y fructificación. Flores abril-agosto, aromáticas en la noche, con olor suave, similar al jazmín o al limón; frutos mayo-diciembre.

Nombres comunes. Mecate, mecatl, cheche, palma, chijute, chiyute y maguey.

Usos. Artesanal, de las hojas se extraen fibras para hacer mecates, redes y canastos, las hojas secas se rasgan para amarrar diversos objetos. Es común plantarlas en cercas vivas junto con otras agaváceas útiles, como Beschorneria albiflora, Furcraea niquivilensis y Yucca elephantipes. En Guatemala con las hojas se elaboran adornos religiosos, como cruces, coronas y arcos conmemorativos.

Especímenes examinados. CHIAPAS. Mpio. El Porvenir, Cerro Mozotal, 5-04-1986, A. Garcia-M. y E. Martínez 2174 (MEXU); Mpio. Motozintla, Las Salvias, 17-12-1987, A. Garcia-M. y E. Martinez 3563, 3565 (MEXU); Mpio. Unión Juárez, El Chiquihuite, 18-121987, A. Garcia-M. y E. Martínez 3570 (MEXU); Mpio. Motozintla, Niquivil, 2-04-1997, A. García-M. et al. 6447, 6450, 6453, 6454 (MEXU); 2-05-1998, A. Garcia-M. et al. 6600, 6602, 6604 (MEXU); Mpio. Unión Juárez, Volcán Tacaná, 5-02-1987, E. Martínez 19468 (MEXU); sin fecha, E. Martinez 20528 (MEXU); El Porvenir, 2605-1967, E. Matuda 37562 (ENCB, MEXU); 15-02-1969, E. Matuda 37583 (MEXU); Pizarrín, 15-02-1969, E. Matuda 37604 (MEXU); Siltepec, Rodeo, 1-5-08-1941, E. Matuda 4566 (MEXU). GUATEMALA. Depto. San Marcos, Volcán Tacaná, 19-12-1987, A. García-M. y E. Martínez 3575, 3576 (MEXU); Depto. El Quiché, Tecpan, 17-08-1996, A. Garcia-M. et al. 6268, 6269 (MEXU); Mpio. Chichicastenango, Chumanzana, 17-08-1996, A. Garcia-M. et al. 6270 (MEXU); Depto. Sololá, Utatlán, Pajaj, 18-08-1996, A. Garcia-M. et al. 6279, 6280 (MEXU); Depto. Totonicapán, Rancho Teja, 18-081996, A. García-M. et al. 6286 (MEXU); Depto. Quezaltenango, Zunil, 20-08-1996, A. Garcia-M. et al. 6299 (MEXU); Guisha, 20-04-1965, H.S. Gentry y E. Schieber 20795 (TEX); Depto. Sololá, Los Encuentros, 1210-1965, H.S. Gentry 21397 (US); Huehuetenango, near Toquia, 04-1970, B. Krukoff 603 (F, GH, K, NY, US); Quezaltenango, 27-05-1970, E. Matuda 38027 (ENCB, MEXU); Totonicapán, 24-05-1972, E. Matuda 38437 (MEXU); Depto. Huehuetenango, El Mirador, 18-061976, D. Smith 132 (F); Chupal, Santa Cruz Quiché, 7-09-1973, M. Sousa et al. 4231 (MEXU); Los Encuentros, 11-01-1939, P.C. Standley 62449 (F); Depto. Quezaltenango, Sijá, 20-02-1939, P.C. Standley 65946 (F); Depto. San Marcos, El Boquerón, 22-02-1939, P.C.
Standley 66289 (F); Depto. Quezaltenango, Palestina, 22-02-1939, P.C. Standley 66372 (F); Volcán de Santa María, Palojunoj, 6-03-1939, P.C. Standley 67548 (F); Depto. Huehuetenango, El Mirador, 31-12-1940, P.C. Standley 81893 (F); Volcán de Santa María, 15-01-1941, P.C. Standley 83401 (F); San Juan Ostuncalco, 21-011941, P.C. Standley 84200 (F); Palestina, 21-01-1941, P.C. Standley 84268 (F); Totonicapán, 23-01-1941, P.C. Standley 84393 (F); San Juan Ostuncalco, 30-01-1941, P.C. Standley 85249 (F); Volcán Zunil, 3-02-1941, P.C. Standley 85757 (F); Volcán Santo Tomás, 24-01-1940, J. Steyermark 34802 (F); Volcán Tacaná, 22-02-1939, J. Steyermark 36473 (F).

Furcraea macdougallii Matuda, Cact. Suc. Mex. 1(2):24, f. 15-17. 1955. TIPO. MÉXICO. Oaxaca, $6 \mathrm{~km}$ al N del puente río Hondo, de la carretera Cristóbal Colón. $60 \mathrm{~km}$ al $\mathrm{NE}$ de Tehuantepec, $1000 \mathrm{~m}, 20$ nov. 1953 (fl), T. MacDougall 269 (LECTOTIPO: MEXU! 160228; ISOLECTOTIPOS: MEXU! 50190, 75958, designados aquí). Figura 7.

Plantas monocárpicas, arborescentes, troncos 6-9 x 0.3$0.7 \mathrm{~m}$, simples, con una roseta de hojas en el ápice, diámetro de la roseta 4-6 $\mathrm{m}$; $80-120$ hojas por roseta. Hojas $140-180(-200) \times 6-10 \mathrm{~cm}$, lineares, erectas, coriáceas, verde-oscuras, persistentes a lo largo del tronco, superficie escabrosa en haz y envés, papilosa, base 4-7 $\mathrm{cm}$ de ancho, ovoide en corte transversal, hasta $8 \mathrm{~cm}$ de grosor, ápice endurecido, en ocasiones con mucrón de $1 \mathrm{~mm}$, rojizo o amarillento; margen dentado-córneo o dentado-denticulado; dientes 2-4 mm de largo, 3-4 mm de ancho en la base, antrorsos, rojizos con la base amarillenta, separados entre sí por (1-)2$5 \mathrm{~cm}$ a la mitad de la hoja, y por $0.5-2 \mathrm{~cm}$ en su tercio inferior. Panículas 5-9 $\mathrm{m}$ de alto, bulbilíferas, romboidales; pedúnculos $1.5-3.5 \mathrm{~m}$ de longitud, verdes, glabros; brácteas 30-65 x 5.5-8 cm, triangulares, semicarnosas, dentadas, verdes; 40-70 ramas primarias, 1-1.5 $\mathrm{m}$ de largo, glabras a algo puberulentas, ramas secundarias (6-) $15-30 \mathrm{~cm}$ de largo, puberulentas a tomentosas, ramas terciarias menores a $15 \mathrm{~cm}$, ocasionales, tomentosas; brácteas de la base de las ramas primarias 10-18 x 4-5 cm, triangulares, dentadas, glabras, brácteas de las ramas secundarias 0.6-1 x 0.5-0.8 $\mathrm{cm}$, deltoides, caedizas, puberulentas hacia el ápice, brácteas de la base de los fascículos florales 0.3-0.5 x 0.2-0.4 cm, deltoides, escariosas, más cortas que los pedicelos, bractéolas inconspicuas, escariosas. Flores 3.5-4 cm de largo, en fascículos de 2-4; pedicelos 0.2$0.6(-1) \mathrm{cm}$, puberulentos; tépalos externos 1.5-2 x 0.3$0.4(-0.6) \mathrm{cm}$, glabrescentes por fuera, los internos $1.5-2$ x 0.4-0.6 $(-0.8) \mathrm{cm}$, glabrescentes sobre la vena media, angostamente elípticos, blanquecinos por fuera, 


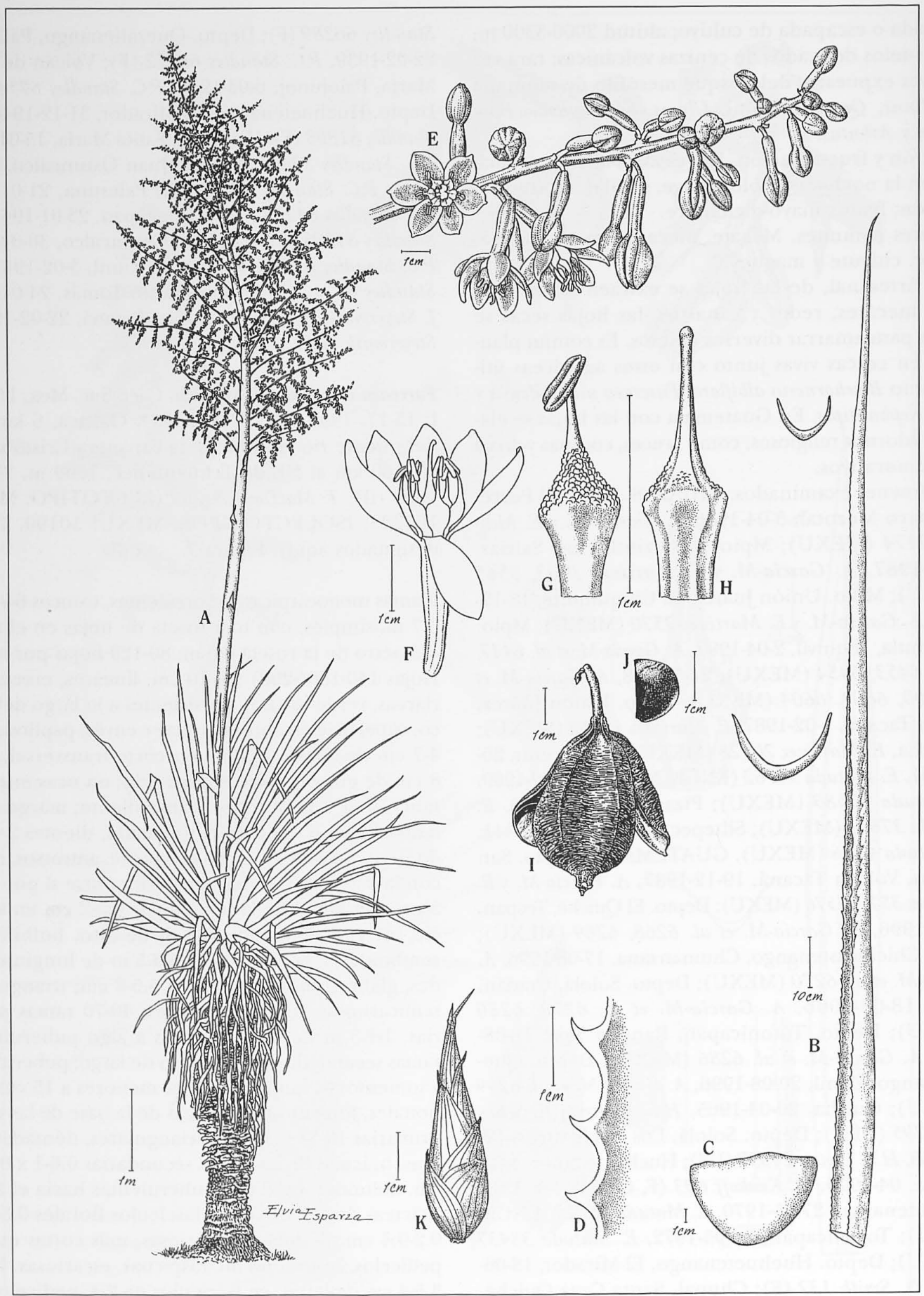

Figura 7. Furcraea macdougallii Matuda. A. Planta con inflorescencia. B. Hoja. C. Secciones transversales. D. Detalle del margen. E. Ramilla secundaria con flores. F. Flor. G. Estambre. H. Estilo. I. Cápsula. J. Semilla. K. Bulbilo bracteado. Ilustración basada en los especímenes Garcia-Mendoza et al. 5742, 5786, 6061 y 6381. 
amarillentos por dentro; estambres 0.9-1.2 cm de largo, 2-3 $\mathrm{mm}$ en su parte más engrosada, amarillentos; anteras 2-2.5 x $1.5 \mathrm{~mm}$, amarillas; ovario $1.3-2.3 \times 0.2-$ $0.3 \mathrm{~cm}$, cilíndrico, puberulento, verde-amarillento; cuello 5-8 mm, glabrescente; estilo $1.3-1.6 \mathrm{~cm}$ de largo, base 3-4 mm; estigma superficialmente trilobado. Cápsulas 4-5 x 3-3.5 cm, oblongas, rostro $5 \mathrm{~mm}$; pedicelos 2-2.3 cm de largo. Semillas $11-13$ x 7-9 mm, ala 1-2 mm, negras, brillantes. Bulbilos bracteados, 4$7(-8.5) \mathrm{cm}$ de alto, $1.2-1.6 \mathrm{~cm}$ de ancho, cónicos, cubiertos con 5-8 brácteas deltoides, verdes, las cercanas a la base escariosas, caedizas.

Furcraea macdougallii se reconoce por sus hojas lineares, con una relación ancho/largo de 1:19-21 (-30), superficie escabrosa, margen dentado-denticulado o dentado córneo y bulbilos cónicos. Matuda (1955) menciona una espina terminal gruesa, característica que no se encontró en las plantas vistas. La especie aparentemente ya se extinguió en la naturaleza y solo sobrevive en forma cultivada.

Distribución y hábitat. MEXICO. Oaxaca y Puebla (figura 8). Laderas con selva baja caducifolia espinosa en el Istmo de Tehuantepec; cultivada en los límites de Oaxaca y Puebla, entre los 750-1800 m, sobre suelos arenosos de origen calizo.

Floración y fructificación. Flores septiembre-diciembre; frutos y bulbilos febrero-mayo. Especie con floraciones esporádicas.

Nombres comunes. Maguey de pescadillo y maguey. Usos. Como cerca viva; antiguamente los jugos de las hojas machacadas se usaron como sustitutos del jabón o se arrojaban a los ríos para hacer flotar a los peces; las inflorescencias se utilizan como forraje.

Especímenes examinados. OAXACA. Dto. Huajuapan, Chazumba, 6-05-1997, A. Garcia-M. y L. de la Rosa 6502 (MEXU); $10 \mathrm{~km}$ al $\mathrm{N}$ de Huajuapan, 6-05-1997, $A$. Garcia-M. y L. de la Rosa 6504 (MEXU); S of Coyul highway to Tehuantepec, 6-12-1965, H.S. Gentry 21885 (MEXU, MICH); Dto. Huajuapan, Huajolotitlán, 1408-1986, F. Palma 82 (MEXU). PUEBLA. Tehuitzingo, 26-10-1990, A. Garcia-M. 5253 (MEXU); Petlalcingo, 19-10-1992, A. Garcia-M. y F. Palma 5742 (MEXU); Chila, 5-02-1993, A. Garcia-M. 5786 (MEXU); Petlalcingo, 25-11-1996, A. García-M. y L. de la Rosa 6381 (MEXU); Chila, 6-05-1997, A. Garcia-M. y L. de la Rosa 6505 (MEXU); Petlalcingo, 6-05-1997, A. Garcia-M. y L. de la Rosa 6506 (MEXU); Mpio. Acatlán, Nuevos Horizontes,7-05-1997, A. Garcia-M. y L. de la Rosa 6507 (MEXU); NW of Tehuitzingo, 6-09-1952, H.S. Gentry 12119 (MEXU).

Furcraea niquivilensis Matuda ex García-Mend., Novon 9:42, figura 1. 1999. TIPO. MÉXICO. Chiapas, Mpio. Motozintla, Barrio Tuchamen, $10 \mathrm{~km}$ al S de Niqui- vil camino a Pavincul, alt. 2347 m, 2 abr 1997 (fl), A. García-Mendoza, L. de la Rosa y A. Castañeda 6441 (HOLOTIPO: MEXU!; ISOTIPOS: ENCB!, K!, MO!).

Hojas (170-) 190-210 x 12-14 cm, mucrón 1-2(-3) mm de largo; margen dentado, dientes 5-6(-8) mm de largo. Panículas 6-9 $\mathrm{m}$ de alto, bulbilíferas, piramidales, abiertas; brácteas del pedúnculo $50 \times 5 \mathrm{~cm}$, triangulares, dentadas, mucronadas; 55 ramas primarias; brácteas de las ramas primarias, 20 x $3.5 \mathrm{~cm}$. Flores 6.5-7.5 (-8) cm; pedicelos 4-8 mm; tépalos externos 3.54 x 0.7-1(-1.3) cm, elípticos, glabrescentes, los internos 3.5-4 x 0.8-1.3 cm, elípticos, pilósulas; estambres 2-2.5 cm de largo, $3-5 \mathrm{~mm}$ en su parte más engrosada; ovario $3-3.5 \times 0.3-0.6 \mathrm{~cm}$, cilíndrico, puberulento; estilo $2-2.3 \mathrm{~cm}$ de largo, 0.4-0.6 mm en la base. Cápsulas 6.5-7 x $4 \mathrm{~cm}$, oblongas. Semillas 1.8-1.9 x 1$1.2 \mathrm{~cm}$, ala $4-5 \mathrm{~mm}$ de ancho. Bulbilos bracteados, 5 $7(-11) \mathrm{cm}$ de alto, 4.5-6.5 $\mathrm{cm}$ de ancho, esferoides a ampliamente cónicos, cubiertos con 4-6 brácteas ampliamente ovadas, pardas a verdes, ocasionalmente con tintes rojizos, cartáceas, persistentes.

Se proporcionan datos morfológicos adicionales a la publicación original.

Distribución y hábitat. MÉXICO. Chiapas (figura 8). Endémica del Municipio de Motozintla, posiblemente también en Guatemala. Cultivada en las faldas del volcán Tacaná, en altitudes de 2000-2650 m, sobre suelos arenosos de origen volcánico. Esta especie al igual que $F$. macdougallii pareciera haberse extinguido de la naturaleza.

Floración y fructificación. Flores abril-mayo, aromáticas y nectaríferas durante la noche, con olor suave parecido al limón, durante el día las flores son visitadas por colibríes, aunque no se ha observado presencia de néctar; frutos y bulbilos mayo-julio.

Nombre común. Maguey.

Usos. Artesanal, con las fibras se hacen cuerdas y se amarran canastos; se plantan al borde de los terrenos para evitar la erosión de los suelos.

Especímenes adicionales. CHIAPAS. Mpio. Motozintla, Pinabeto, 2-05-1998, A. García-M. et al. 6596, 6597 (MEXU); Mpio. Motozintla, Tuxamen-Chekansé, 2-051998, A. Garcia-M. et al. 6599 (MEXU, QMEX).

\section{Agradecimientos}

Agradezco la revisión cuidadosa del manuscrito y las discusiones nomenclaturales a Fernando Chiang, quien además hizo la diagnosis latina de Furcraea martinezii. A la CONABIO, que a través del proyecto H111, proporcionó equipo y financió colectas en México y Guatemala. A los curadores de los herbarios B, BM, C, CIMI, ENCB, F, G, GH, IBUG, IEB, K, M, MEXU, 


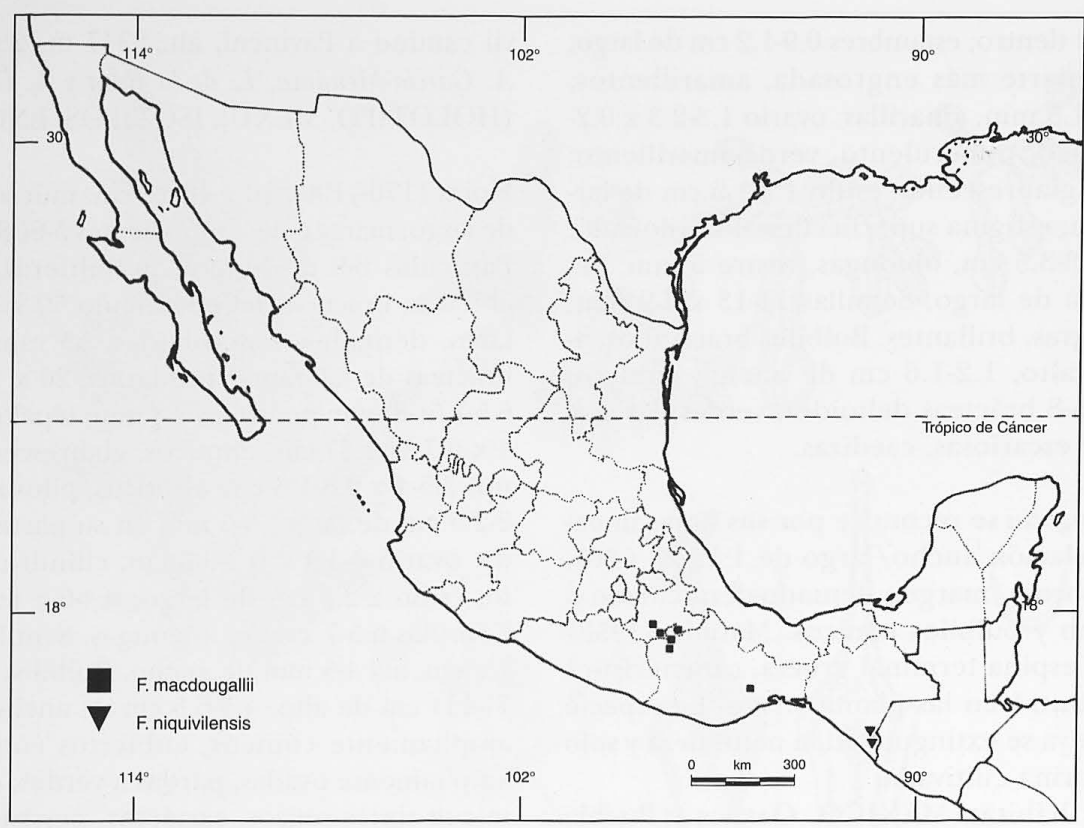

Figura 8. Distribución de Furcraea macdougallii y F. niquivilensis.

MICH, MO, NY, QMEX, TEX, UAMIZ, UC, US, WIS y ZEA, por los préstamos del material consultado. A los Drs. Bert Leuenberger del herbario de BerlínDahlem, Grau Juerke del herbario de Munich y Lourdes Rico de los Jardines Botánicos Reales de Kew por el envío de información y sus comentarios acerca del material tipo. A Heike Vibrans y Mahinda Martínez por su ayuda en la traducción de textos del alemán. A Laura de la Rosa, Alejandro Castañeda, Alejandro Gutíerrez, Sonia Franco y Felipe Palma por su valiosa ayuda en las colectas de campo. De manera especial, a Elvia Esparza por las excelentes ilustraciones y a Felipe Villegas por la elaboración de los mapas.

\section{Literatura Citada}

Álvarez de Zayas A. 1986. Las inflorescencias de Agavaceae. Revista del Jardín Botánico Nacional de Cuba 7(2):3-14.

Álvarez de Zayas A. 1996. El género Furcraea (Agavaceae) en Cuba. Anales del Instituto de Biologia, Serie Botánica $67(2): 329-346$.

Baker J.G. 1879. The species of Fourcroya. The Gardeners' Chronicle (Serie 2) 11:623-624, 656.

Baker J.G. 1888. Handbook of Amaryllideae. London.

Cházaro-Basañez M.J. 1989. Agavaceae del centro de Veracruz y zona limítrofe de Puebla. Cactáceas y Suculentas Mexicanas 34:3-14.
Dahlgren R.M., Clifford H.T. y Yeo P.F. 1985. The Families of The Monocotyledons. Springer-Verlag. Berlin.

Drummond J.R. 1907. The literature of Furcraea with a synopsis of the known species. Repertorium Missouri Botanical Garden 18:25-75, tab.1-4.

García-Mendoza A. 1995. Riqueza y endemismos de la familia Agavaceae en México. En: Linares-Mazari E. et al. Eds. Conservación de plantas en peligro de extinción: Diferentes enfoques. Universidad Nacional Autónoma de México, Instituto de Biología, México D.F., 59-83.

García-Mendoza A. y Galván-Villanueva R. 1995. Riqueza de las familias Agavaceae y Nolinaceae en México. Boletín de la Sociedad Botánica de México 56:7-24.

García-Mendoza A. y Lott J.E. 1994. Furcraea Vent. En: Davidse G. et al. Eds. Flora Mesoamericana. Volumen 6. Universidad Nacional Autónoma de México, Instituto de Biología, México D.F., 45-47.

Holmgren P.K., Holmgren N.H. y Barnett L.C. 1990. Index Herbariorum. Part 1. The herbaria of the world. New York Botanical Garden. New York.

Jacquin N.J. 1760. Agave hexapetala. Enumeratio Systematica Plantarum. Lugduni Batavorum, Leiden, 18.

Koch K. 1862. Uber die Tonel'schen Agaveen in Gent. Wochenschrift für Gärtnerei und Plfanzenkunde 5(25):197199.

Koch K. 1863. Ueber Furcraea, besonders F. bedinghausi C. Koch. Wochenschrift für Gärtnerei und Plfanzenkunde 6(30):233-235. 
Lineo C. 1753. Agave foetida. Species Plantarum. Volumen 1. London, 323-324.

MacDougall T. 1964. Two tree Furcreas. Cactus and Succulent Journal of The Cactus and Succulent Society of America 36(4):116-117.

Ortgies E. 1859. Catalog mexicanischer pflanzen und Samerein, von B. Roezl u. comp., Handelsgärtner in Mexico. Gartenflora 8:276-278.

Roemer M.J. 1846. Fourcroya. Synopses monographicae. Fasc. I. Vimariae, 292-295.

Roezl B. 1881. Mitteilungen ueber die vertvollsten der von mir in Nord, Zentral, und Sued Amerika sowie in Westindien entedeckten und in Europa eingefuehrten pflanzen. Deutsche Gärtner-Zeitung 5:154-156.

Roezl B. 1883. Notes sur les découvertes botaniques les plus remarquables faites en Amérique. Belgique Horticole 33:133.

Trelease W. 1915. The Agaveae of Guatemala. Transactions Academy of Sciences of St. Louis 23(3):129-152, tab.6-35.

Trelease W. 1920. Furcraea. En: Standley P.C. Ed. Trees and shrubs of Mexico. Contributions from the United States National Herbarium 23(1):105-107.
Ullrich B. 1991. Notas sobre la publicación del género Furcraea Ventenat (Agavaceae). Cactáceas y Suculentas Mexicanas 36(1):8-9.

Ullrich B. 1991 a. El complejo Furcraea longaeva Karwinski et Zuccarini. Cactáceas y Suculentas Mexicanas 36(2):3036.

Ullrich B. 1991 b. El complejo Furcraea longaeva Karwinski et Zuccarini II. Cactáceas y Suculentas Mexicanas 36(3):5661.

Ullrich B. 1991c. El complejo Furcraea longaeva Karwinski et Zuccarini III. Cactáceas y Suculentas Mexicanas 36(4):7983.

Ventenat E.P. 1793. Furcraea Novum Plantae Genus descriptum. Bulletin de la Societé Philomatique, a ses Correspondans 28. (Vendemiaire an 2 de la Rep. Oct. 1):1-3.

Ventenat E.P. 1796. Furcraea Novum Plantae Genus descriptum. Annalen der Botanik (Usteri) 19 (Neue Ann. Bot. 13):5460.

Willemet P.R.F. de P. 1796. Funium pitiferum, Herbarium Mauritianum. Annalen der Botanik (Usteri) 18 (Neue Ann. Bot. 12):26-27. 